\title{
Effect of a high protein/low glycaemic index diet on insulin resistance in adolescents with overweight/ obesity-A PREVIEW randomized clinical trial
}

\author{
Elke Dorenbos $^{1,2}$ @ | Mathijs Drummen ${ }^{1} \quad$ | Tanja Adam ${ }^{1}$ | Jesse Rijks ${ }^{2}$ | \\ Bjorn Winkens $^{3}$ ｜ J. Alfredo Martínez ${ }^{4,5,6}$ | Santiago Navas-Carretero ${ }^{4,5}$ | \\ Gareth Stratton $^{7}$ | Nils Swindell ${ }^{7}$ | Pauline Stouthart ${ }^{2}$ | Kelly Mackintosh ${ }^{7}$ | \\ Melitta Mcnarry ${ }^{7}$ | Angelo Tremblay ${ }^{8}$ | Mikael Fogelholm ${ }^{9}$ | Anne Raben ${ }^{10}$ | \\ Margriet Westerterp-Plantenga $^{1}$ | Anita Vreugdenhil ${ }^{1,2}$ () \\ ${ }^{1}$ NUTRIM School of Nutrition and Translational Research in Metabolism, Maastricht University, Maastricht, The Netherlands \\ ${ }^{2}$ Centre for Overweight Adolescent and Children's Healthcare (COACH), Maastricht University Medical Centre, Maastricht, The Netherlands \\ ${ }^{3}$ Department of Methodology and Statistics, Care and Public Health Research Institute (CAPHRI), Maastricht University, Maastricht, The Netherlands \\ ${ }^{4}$ Department of Nutrition, Food Science and Physiology, Centre for Nutrition Research (CIN), Universidad de Navarra, Pamplona, Spain \\ ${ }^{5}$ CIBERobn, Instituto de Salud Carlos III, Madrid, Spain \\ ${ }^{6}$ IMDEA Research Institute on Food and Health Sciences, Madrid, Spain \\ ${ }^{7}$ Research Centre in Applied Sports, Technology, Exercise and Medicine (A-STEM), Swansea University, Swansea, UK \\ ${ }^{8}$ Department of Kinesiology, Université Laval, Québec, Canada \\ ${ }^{9}$ Department of Food and Nutrition, University of Helsinki, Helsinki, Finland \\ ${ }^{10}$ Department of Nutrition, Exercise and Sports, Faculty of Science, University of Copenhagen, Frederiksberg, Denmark
}

Correspondence

Anita Vreugdenhil, Centre for Overweight Adolescent and Children's Healthcare, Department of Paediatrics, Maastricht University Medical Centre, P. Debyelaan 25, 6229 HX Maastricht, The Netherlands.

Email: a.vreugdenhil@mumc.nl

Funding information

FP7 Food, Agriculture and Fisheries,

Biotechnology, Grant/Award Number: 312057

\section{Summary}

Background: Pubertal insulin resistance (IR) is associated with increased risk of type 2 diabetes mellitus development in adolescents with overweight/obesity.

Objectives: The PREVIEW study was a randomized parallel trial assessing the change in IR, analyzed by Homeostatic Model Assessment of IR (HOMA-IR), at 2 years after randomization to a high protein vs a moderate protein diet in adolescents with overweight/obesity. It was hypothesized that a high protein/low glycaemic index diet would be superior in reducing IR compared to a medium protein/medium GI diet, in insulin resistant adolescents with overweight or obesity.

Methods: Adolescents with overweight/obesity and IR from the Netherlands, United Kingdom and Spain were randomized into a moderate protein/moderate GI (15/55/ $30 \mathrm{En} \%$ protein/carbohydrate/fat, $\mathrm{Gl} \geq 56$ ) or high protein/low GI (25/45/30En\% protein/carbohydrate/fat, $\mathrm{Gl}<50$ ) diet. Anthropometric and cardiometabolic parameters, puberty, dietary intake and physical activity (PA) were measured and effects on HOMA-IR were analyzed. 
Results: 126 adolescents were included in this study $(13.6 \pm 2.2$ years, BMI z-score $3.04 \pm 0.66$, HOMA-IR $3.48 \pm 2.28$, HP $n=68, M P n=58$ ). At 2 years, changes in protein intake were not significantly different between timepoints or intervention groups and no effects of the intervention on IR were observed. The retention rate was $39 \%$, while no compliance to the diets was observed.

Conclusions: The PREVIEW study observed no effect of a high protein/low GI diet on IR in adolescents with overweight/obesity and IR because of lack of feasibility, due to insufficient retention and dietary compliance after 2 years.

\section{KEYWORDS}

dietary protein, glycaemic index, glycaemic load, physical activity, pubertal insulin resistance

\section{INTRODUCTION}

The prevalence of childhood obesity has rapidly increased over the last decades and, without adequate management, is expected to rise to approximately 268 million children globally in 2025 with a subsequent increase in obesity-related comorbidities. ${ }^{1-3}$ During puberty, transient insulin resistance (IR) is a common physiological phenomenon. ${ }^{4-9}$ IR is defined as reduced ability of insulin to increase glucose uptake and utilization, resulting in a compensatory increase in insulin secretion to maintain normal blood glucose concentrations. ${ }^{7}$ A transient increase in IR during puberty is considered to be a physiological phenomenon of growth, but especially adolescents with obesity show an exaggerated increase in IR. In addition, in adolescents with obesity, IR does not appear to decrease at the end of puberty as is observed in lean adolescents. ${ }^{5,6,9}$ Particularly adolescents with obesity therefore may have increased risk for $\beta$-cell exhaustion and development of T2DM even at a young age. ${ }^{5}$ Furthermore, it has been shown that both obesity and IR are associated with development of cardiovascular disease, for example, dyslipidaemia and hypertension even in childhood. $^{8,10}$ Moreover, adolescents with IR were less successful in decreasing BMI z-score in response to interventions than adolescents that are not insulin resistant. ${ }^{4,11}$ Thus, particularly in adolescents with overweight or obesity and increased IR, interventions should focus on decreasing BMI z-score and assess whether the increase of Homeostatic Model Assessment of IR (HOMA-IR) during pubertal IR can be attenuated.

Recommendations of the US Preventive Services Task Force and others include comprehensive, multidisciplinary lifestyle interventions for treatment of obesity in children, although there is no consensus on the most efficient and effective type of dietary and physical activity (PA) strategy. ${ }^{11,12}$ Earlier observations report that a relative increase of dietary protein, thereby reducing fat and carbohydrate intake, led to a significant reduction in obesity. ${ }^{11-18}$ Two studies showed that a higher-protein diet reduced IR significantly. ${ }^{12,17}$ One study that combined increased protein intake with decreased glycaemic index (GI) observed a significant reduction in percentage of children with overweight/obesity in this group compared to control diets. ${ }^{17}$ Proposed underlying mechanisms for these effects might be the ability of protein to increase satiety, thermogenesis and fat-oxidation, thus reducing fat mass while maintaining fat free mass during energy restriction. ${ }^{19}$ Lowering $\mathrm{Gl}$ in diets has been suggested to promote satiety and reduces hunger, although few long-term studies have been performed in adolescents to confirm these effects. ${ }^{20}$ In addition, PA alone and in combination with a dietary intervention, has been shown to change body composition by increasing fat free mass, and reducing fat mass, fasting glucose concentrations and IR. $^{21-23}$ Especially lifestyle interventions combining diet, PA, and behavioural strategies have been effective in decreasing obesity and reducing IR and cardiovascular risk parameters in youths. ${ }^{22}$ However, studies researching the effects of combined lifestyle intervention in adolescents with overweight/obesity and increased IR are scarce. Thus far, three large community studies have been performed aiming to decrease IR parameters in adolescents with overweight/obesity, of which two showed significant favourable changes in glucose metabolism abnormalities and BMI zscore after short-term, intensive intervention. ${ }^{24-26}$ However, lifestyle interventions in adolescents in free-living conditions often report problems with participants meeting dietary targets and maintaining PA levels. ${ }^{26,27}$ Specifically, previous studies aiming to increase relative protein intake reported difficulties in dietary compliance and participants meeting protein targets, and were mostly conducted under controlled settings (eg, meal observation in in-centre settings). ${ }^{11,13-18}$ Therefore, the effect of a lifestyle intervention of a high protein/low GI diet in adolescents with overweight/obesity and increased IR, should be addressed in real-life settings.

The PREVention of diabetes through lifestyle Intervention and population studies in Europe and around the World (PREVIEW) study in adolescents was a randomized clinical study assessing the change in $\mathrm{IR}$, analyzed as HOMA-IR, at 2 years after randomization to a high protein/low GI vs a moderate protein/moderate GI diet, in adolescents with overweight/obesity. It was hypothesized that a high protein/low GI diet would be superior in reducing IR compared to a medium protein/medium GI diet, in insulin resistant adolescents with overweight or obesity. In addition, in both diet groups PA was encouraged and monitored. 


\section{2 | MATERIALS AND METHODS}

\section{1 | Study design}

The PREVIEW study in adolescents was a multicentre, 104-week parallel-group, gender-stratified block-randomized (10:10) trial between December 2013 and December 2018, as described previously. ${ }^{28}$ The first 8 weeks aimed at weight stabilization during growth. All participants received sample menus based on their estimated energy requirements, consisting of 15/55/30 energy percent (En\%) protein/carbohydrate/ fat. ${ }^{29}$ In the second phase, adolescents were randomized into a moderate protein/moderate GI (MP) or a high protein/low GI (HP) group. Randomization was stratified by sex, age and centre in blocks of 10 using a computerized randomization tool. The MP group received a sample menu with a macronutrient composition of 15/55/30 En\% protein/carbohydrate/fat and a $\mathrm{Gl} \geq 56$. The HP group received a sample menu with a target macronutrient composition of 25/45/30 En\% protein/carbohydrate/ fat and $\mathrm{a} \mathrm{Gl} \leq 50$. All menus were tailored to the participant's estimated energy requirements. Upon request, further personalized tips were given taking for example, cultural traditions into account. In addition, in the perspective of pre-diabetes related health, participants were instructed to increase PA (in organized sports and daily movement). Due to the personalized instructions for participants during the measurement meetings, participants and research staff could not be blinded. The study was designed as a 2 years randomized clinical trial. The study protocol was approved by local Medical Ethics Committees at all study sites. The study was compliant with the Declaration of Helsinki and ICH-GCP.

\section{2 | Participants}

Adolescents were recruited from three study sites (Maastricht University, the Netherlands; University of Navarra, Spain and Swansea University, UK) between December 2013 and December 2016 by ED, NS and SNC. Inclusion criteria were overweight/obesity (BMI z-score $>1.0$ SDS), increased IR (defined as HOMA-IR >2.0 for adolescents Tanner G/M stages $\geq 3$ or any HOMA-IR for adolescents at Tanner stages 1-2) and signed informed consent from both parents and adolescents $\geq 12$ years. ${ }^{28}$ Exclusion criteria included medical conditions or use of medication that might influence study outcomes (eg, T2DM, bariatric surgery and use of metformin) or compromise study adherence (eg, severe food intolerances or musculoskeletal diseases).

\section{3 | Measurements}

\subsection{1 | Anthropometric characteristics and body composition}

Height and weight were measured at baseline, after 1 and 2 years while participants were barefoot, wearing only underwear and in a fasted state, and subsequently BMI was calculated. Because BMI in adolescents is not a representative measure of obesity status due to periods of growth, age- and gender-adjusted BMI z-scores were calculated (TNO Growth Calculator, TNO, Den Haag, the Netherlands). ${ }^{30}$ Body composition was measured with air-displacement plethysmography (at Maastricht University: BodPod, Life Measurement Instruments, Concord, California) using the Lohman algorithm, bio-impedance measurements (at University of Navarra: BIA, Tanita SC-330. Tanita Corp, Tokyo, Japan), or dual energy $x$-ray absorptiometry (at Swansea University: DEXA, Stratos dR, Medimaging UK). ${ }^{31}$ Pubertal stage was determined with the Tanner genital (boys) or mammary (girls) scale. ${ }^{32,33}$

\subsubsection{Glucose metabolism}

Blood samples were obtained by venepuncture after an overnight fast by trained healthcare professionals. All samples were centrifuged and frozen locally, and subsequently analysed at the laboratory for clinical chemistry at Maastricht University. Concentrations of fasting blood glucose were analysed with the COBAS 800 modular analyser (Roche, Woerden, the Netherlands). Fasting insulin and HbA1c concentrations were determined using the fully automated HPLC Variant II 155 (Bio-Rad Laboratories, Veenendaal, the Netherlands) and C-peptide concentrations with the Immulite XPI (Siemens, Eindhoven, the Netherlands). An index for IR was calculated using HOMA-IR (fasting glucose concentration $(\mathrm{mmol} / \mathrm{L}) \times$ fasting insulin concentration $(\mathrm{mU} / \mathrm{L}) / 22.5) .^{34}$

\subsection{3 | Compliance: Food intake and PA}

Compliance to the dietary instructions was assessed using four-day food records, provided at each measurement visit, and which were subsequently analysed for energy intake, macronutrient composition including protein content (both $\mathrm{g} / \mathrm{d}$ as En\%), fibre content, $\mathrm{Gl}$ and glycaemic load (GL) using the Eetmeter food diary and analysis tool (Voedingscentrum, Den Haag, the Netherlands). Compliance to the diet was further assessed by the Three Factor Eating Questionnaire (TFEQ), consisting of the three factors cognitive restraint of eating, disinhibition and hunger, where increase in cognitive restraint, and decreases in disinhibition and hunger are indicators for successful dieting in general. ${ }^{35-38}$ To assess underreporting, reported total energy intake was compared to the daily energy requirements for children and adolescents using the WHO formula to assess underreporting [total energy expenditure $(\mathrm{MJ} /$ day $)=1.298+$ $0.265 \mathrm{~kg}-0.0011 \mathrm{~kg}^{2}$ (boys) or $1.102+0.273 \mathrm{~kg}-0.0019 \mathrm{~kg}^{2}$ (girls)]. ${ }^{29}$ PA was assessed with 7-day accelerometry (Actigraph GT3X accelerometer, Actigraph Corp.) and the Baecke Questionnaire. ${ }^{39}$ Participants were instructed to wear the accelerometer on the right hip during seven full days and nights, only removing the accelerometer during showering, swimming or contact sports. Wear time validation was performed with a minimum of 4 days $>10$ hours including 1 weekendday. Epochs were measured with the length of 10 seconds and Evenson cut-off points were used to assess moderate, light and vigorous activity. ${ }^{40,41}$ 


\subsection{Statistical analyses}

Power calculations were performed using G*power (Dusseldorf University, Dusseldorf, Germany) and adjusted for an estimated 25\% drop-out. With an $\alpha$ of .05 , effect size of .37 for HOMA-IR and sample size of 100 , a power of 0.96 could be achieved. ${ }^{28}$ To remain sufficient power for analyses at 2 years despite drop-out, intention-totreat analyses were performed on the complete dataset after multiple imputation. For this, 50 datasets were created (MICE Package in $\mathrm{R}, \mathrm{v}$ 3.2.3, Vienna, Austria). The maximum number of iterations was set to 20 , where convergence was checked by inspecting the trace lines. The following predictors were used to impute missing values: gender, age, Tanner stage and BMI z-score at baseline and at 1 or 2 years, and the baseline value of the imputed variable. Estimated effect changes over time in the intention-to-treat analyses were pooled from the multiple imputed datasets, analysed using factorial
ANOVA's with repeated measures and presented as mean (95\% confidence interval). As this was an exploratory study, no corrections for multiple comparisons have been made. All statistical analyses were performed using IBM SPSS Statistics for Windows version 24 (IBM Corp., Armonk, New York). A P-value <.05 was considered to be statistically relevant.

\section{$3 \mid$ RESULTS}

\subsection{Characteristics of the participants}

In total, 126 adolescents were included in the baseline analyses between December 2013 and December 2016, as described previously. ${ }^{26}$ After 1 years of intervention 83 participants (66\% retention rate) were still participating, and after 2 years, 49 participants (39\%

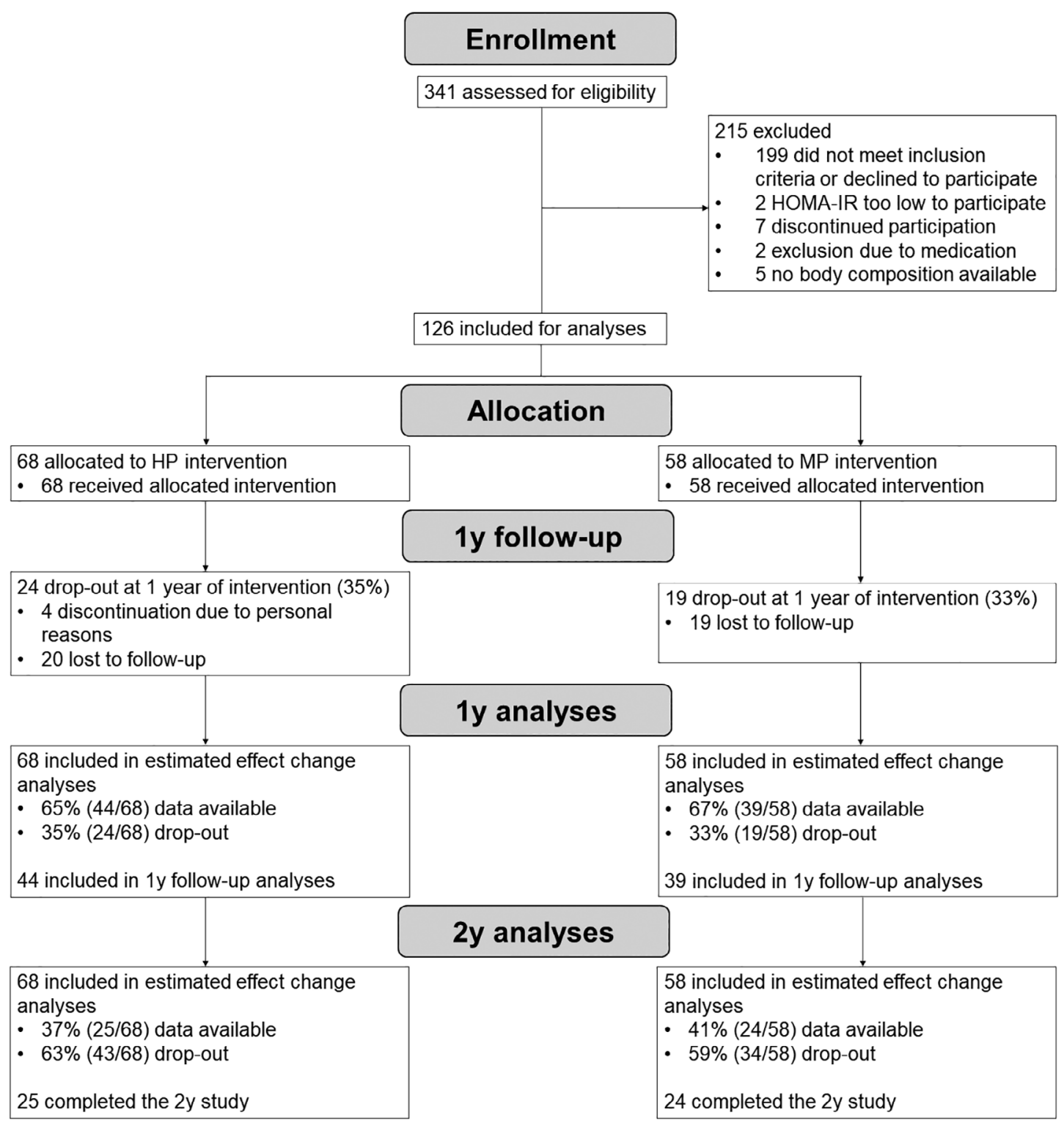

FIGURE 1 Study flowchart 
TAB LE 1 Estimated effect changes in food intake and PA parameters after 1 and 2 years of intervention

\begin{tabular}{|c|c|c|c|c|c|c|}
\hline \multirow[b]{3}{*}{ Outcome } & \multicolumn{2}{|l|}{ Baseline } & \multicolumn{2}{|c|}{$\begin{array}{l}\text { Estimated effect changes after } 1 \mathrm{y} \\
\text { (after multiple imputation) }\end{array}$} & \multicolumn{2}{|c|}{$\begin{array}{l}\text { Estimated effect changes after } 2 \text { y } \\
\text { (after multiple imputation) }\end{array}$} \\
\hline & \multirow{2}{*}{$\frac{\mathrm{HP}(\mathrm{n}=68)}{\text { Mean } \pm \mathrm{SD}}$} & \multirow{2}{*}{$\frac{\mathrm{MP}(\mathrm{n}=58)}{\text { Mean } \pm \text { SD }}$} & \multirow{2}{*}{$\frac{\mathrm{HP}(\mathrm{n}=68)}{\Delta(95 \% \mathrm{Cl})}$} & \multirow{2}{*}{$\frac{\mathrm{MP}(\mathrm{n}=58)}{\Delta(95 \% \mathrm{Cl})}$} & \multirow{2}{*}{$\frac{\mathrm{HP}(\mathrm{n}=68)}{\Delta(95 \% \mathrm{Cl})}$} & \multirow{2}{*}{$\frac{\mathrm{MP}(\mathrm{n}=58)}{\Delta(95 \% \mathrm{Cl})}$} \\
\hline & & & & & & \\
\hline \multicolumn{7}{|l|}{ Food intake } \\
\hline $\mathrm{Gl}$ & $50.9 \pm 7.7$ & $54.3 \pm 8.7$ & $0.0(-4.6,4.6)$ & $-2.7(-7.9,2.6)$ & $-1.4(-3.5,0.6)$ & $-2.8(-5.4,-0.2)^{*}$ \\
\hline Energy intake $(\mathrm{MJ} / \mathrm{d})$ & $6.7 \pm 1.6$ & $7.3 \pm 2.3$ & $-0.9(-1.7,-0.1)^{*}$ & $-1.2(-2.1,-0.3)^{*}$ & $0.0(-0.5,0.5)$ & $-0.6(-1.6,0.1)$ \\
\hline Protein (g/d) & $70.0 \pm 19.2$ & $70.9 \pm 17.4$ & $-6.0(-13.7,-1.8)$ & $-4.4(-11.7,2.8)$ & $-1.7(-6.5,3.0)$ & $-4.3(-10.9,2.2)$ \\
\hline Protein (En\%) & $17.5 \pm 2.4$ & $16.9 \pm 3.7$ & $1.8(-1.1,4.7)$ & $1.8(-0.7,4.4)$ & $-0.5(-2.2,1.2)$ & $0.3(-1.7,2.2)$ \\
\hline Fat $(\mathrm{g} / \mathrm{d})$ & $65.9 \pm 23.5$ & $70.2 \pm 29.3$ & $-9.4(-20.3,1.5)$ & $-12.4(-25.0,0.1)$ & $2.3(-3.4,8.1)$ & $-2.9(-11.2,5.3)$ \\
\hline Fibre $(g / d)$ & $13.9 \pm 5.0$ & $14.1 \pm 6.2$ & $1.0(-1.1,3.2)$ & $-0.7(-2.9,1.4)$ & $-0.1(-2.4,2.1)$ & $0.4(-2.5,3.3)$ \\
\hline \multicolumn{7}{|l|}{ Food intake parameters } \\
\hline $\begin{array}{l}\text { TFEQ cognitive } \\
\text { restraint of eating }\end{array}$ & $10.6 \pm 3.6$ & $11.5 \pm 4.1$ & $1.2(-0.6,3.0)$ & $0.6(-1.5,2.6)$ & $2.4(0.6,4.1)^{* *}$ & $1.8(-0.3,3.9)$ \\
\hline TFEQ disinhibition & $6.7 \pm 3.5$ & $5.4 \pm 3.0$ & $-0.1(-1.5,1.3)$ & $0.6(-0.9,2.0)$ & $0.7(-1.4,2.7)$ & $2.7(0.3,5.1)^{*}$ \\
\hline TFEQ hunger & $5.8 \pm 3.7$ & $4.9 \pm 2.5$ & $-1.0(-3.1,1.0$ & $0.1(-1.5,1.8)$ & $0.8(-1.5,3.1)$ & $2.3(-0.4,5.0)$ \\
\hline \multicolumn{7}{|l|}{ PA parameters } \\
\hline Baecke school & $2.4 \pm 0.3$ & $2.6 \pm 0.4$ & $0.1(0.0,0.2)$ & $-0.1(-0.2,0.1)$ & $-0.0(-0.2,0.1)$ & $-0.2(-0.4,-0.0)^{*}$ \\
\hline Baecke sport & $2.7 \pm 0.5$ & $2.8 \pm 0.5$ & $0.1(-0.1,0.3)$ & $0.1(-0.1,0.3)$ & $-0.1(-0.3,0.1)$ & $-0.2(-0.4,0.1)$ \\
\hline $\begin{array}{l}\text { Sedentary behaviour } \\
(\mathrm{min} / \mathrm{d})\end{array}$ & $617.0 \pm 105.8$ & $653.4 \pm 125.0$ & $\begin{array}{l}-165.3(-210.1 \\
-120.6)^{* *}\end{array}$ & $\begin{array}{l}-191.8(-241.7 \\
-141.9)^{* *}\end{array}$ & $\begin{array}{l}-138.9(-180.7 \\
-97.1)^{* *}\end{array}$ & $\begin{array}{l}-178.5(-224.1 \\
-132.9)^{* *}\end{array}$ \\
\hline Light PA (min/d) & $335.0 \pm 7.8$ & $306.7 \pm 69.1$ & $-40.6(69.9,-11.3)^{* *}$ & $-29.6(-59.9,0.8)$ & $-37.1(-71.8,-2.4)^{*}$ & $3.4(-37.9,44.6)$ \\
\hline Moderate PA $(\min / \mathrm{d})$ & $22.2 \pm 13.3$ & $20.3 \pm 16.9$ & $6.7(2.3,11.1)^{* *}$ & $8.0(2.8,13.1)^{* *}$ & $3.0(-2.7,8.7)$ & $7.4(0.8,14 .)^{*}$ \\
\hline Vigorous PA (min/d) & $4.7 \pm 4.8$ & $4.7 \pm 5.4$ & $5.7(2.3,9.1)^{* *}$ & $4.8(1.5,8.2)^{* *}$ & $2.8(0.0,5.6)^{*}$ & $3.8(0.8,6.9)^{*}$ \\
\hline $\begin{array}{l}\text { Moderate-to-vigorous } \\
\text { PA }(\mathrm{min} / \mathrm{d})\end{array}$ & $26.9 \pm 16.4$ & $25.1 \pm 19.2$ & $12.3(6.4,18.2)^{* *}$ & $12.6(5.9,19.4)^{* *}$ & $5.7(3.7,12.1)$ & $11.4(4.0,18.8)^{* *}$ \\
\hline
\end{tabular}

Note: Estimated effect changes are based upon imputated datasets. $P$-values are based upon comparison with baseline values. ${ }^{*} P<.05$; ${ }^{* *} P<.01$.

Abbreviations: BMI, body mass index; cpd, counts per day; cpm, counts per minute; En\%, percentage of total energy intake; FFM, fat free mass; FM, fat mass; GI, glycaemic index; GL, glycaemic load; HOMA-IR, Homeostatic Model Assessment of Insulin Resistance [glucose (mmol/L)/insulin (mU/ L) $\times 22,5-{ }^{34}$ ]; HP, high protein/low glycaemic index; MP, medium protein/medium glycaemic Index; PA, physical activity; TFEQ, Three Factor Eating Questionnaire. $^{35}$

retention rate) completed the study (Figure 1). Reasons for drop-out were discontinuation of the study due to personal reasons $(n=4)$ and loss to follow-up ( $n=77$ ). Baseline characteristics of adolescents who dropped out were not significantly different from adolescents that remained in the study. No serious adverse events were reported.

Baseline descriptives of the HP and MP group are presented in Tables 1 and 2. No significant differences between the groups were observed in gender, BMI z-score, HOMA-IR or other glucose metabolism or lifestyle parameters.

\subsection{Compliance to dietary instructions}

Absolute and relative reported protein intake, as a percentage of total energy intake, were not significantly changed after 1 and 2 years of 
TAB LE 2 Estimated effect changes in anthropometric characteristics, body composition and parameters of glucose metabolism after 1 and 2 years of intervention

\begin{tabular}{|c|c|c|c|c|c|c|}
\hline \multirow[b]{3}{*}{ Outcome } & \multicolumn{2}{|l|}{ Baseline } & \multicolumn{2}{|c|}{$\begin{array}{l}\text { Estimated effect changes after } 1 \text { y } \\
\text { (after multiple imputation) }\end{array}$} & \multicolumn{2}{|c|}{$\begin{array}{l}\text { Estimated effect changes after } 2 \text { y } \\
\text { (after multiple imputation) }\end{array}$} \\
\hline & $\mathrm{HP}(n=68)$ & $\mathrm{MP}(\mathrm{n}=58)$ & $\mathrm{HP}(\mathrm{n}=68)$ & $M P(n=58)$ & $\mathrm{HP}(n=68)$ & MP $(n=58)$ \\
\hline & Mean \pm SD & Mean \pm SD & $\Delta(95 \% \mathrm{Cl})$ & $\Delta(95 \% \mathrm{Cl})$ & $\Delta(95 \% \mathrm{Cl})$ & $\Delta(95 \% \mathrm{Cl})$ \\
\hline \multicolumn{7}{|l|}{ General characteristics } \\
\hline Girls n (\%) & 39 (57.4\%) & 35 (60.3\%) & & & & \\
\hline Age (y) & $13.7 \pm 2.4$ & $13.4 \pm 2.0$ & $1.1(1.1,1.2)^{* *}$ & $1.1(1.1,1.2)^{* *}$ & $2.2(2.0,2.3)^{* *}$ & $2.2(2.0,2.3)^{* *}$ \\
\hline Tanner stage & $3(2-5)$ & $3(2-4)$ & $0.6(0.3,0.8)^{* *}$ & $0.5(0.3,0.8)^{* *}$ & $0.8(0.4,1.2)^{* *}$ & $0.7(0.3,1.1)^{* *}$ \\
\hline \multicolumn{7}{|c|}{ Anthropometric characteristics } \\
\hline Height (m) & $1.61 \pm 0.11$ & $1.60 \pm 0.10$ & $0.05(0.04,0.06)^{* *}$ & $0.05(0.04,0.07)^{* *}$ & $0.08(0.05,0.11)^{* *}$ & $0.09(0.06,0.11)^{* *}$ \\
\hline Weight (kg) & $80.0 \pm 20.9$ & $75.7 \pm 18.2$ & $8.3(1.1,15.5)^{*}$ & $10.6(3.6,17.6)^{* *}$ & $4.4(-1.5,10.4)$ & $3.0(-2.9,8.9)$ \\
\hline $\mathrm{BMI}\left(\mathrm{kg} / \mathrm{m}^{2}\right)$ & $30.1 \pm 5.1$ & $29.3 \pm 4.6$ & $1.3(-1.1,3.6)$ & $2.3(-0.3,4.9)$ & $-0.33(-1.8,1.2)$ & $-0.5(-1.8,0.8)$ \\
\hline BMI z-score (SD) & $3.10 \pm 0.69$ & $2.97 \pm 0.63$ & $-0.22(-0.33,-0.10)^{* *}$ & $-0.09(-0.21,0.03)$ & $-0.16(-0.36,0.04)$ & $-0.22(-0.46,0.01)$ \\
\hline Fat free mass $(\mathrm{kg})$ & $47.5 \pm 12.3$ & $46.2 \pm 10.5$ & $3.0(1.5,4.5)^{* *}$ & $3.6(2.0,5.3)^{* *}$ & $6.8(3.7,9.9)^{* *}$ & $6.0(3.3,8.7)^{* *}$ \\
\hline Fat mass (kg) & $32.4 \pm 12.3$ & $29.3 \pm 11.0$ & $1.0(-0.9,3.0)$ & $2.7(0.7,4.7)^{* *}$ & $5.0(1.4,8.6)^{* *}$ & $4.0(-0.3,8.4)$ \\
\hline Fat mass (\%) & $40.0 \pm 7.4$ & $38.2 \pm 8.9$ & $-1.1(-4.7,2.5)$ & $-0.5(-3.8,2.9)$ & $1.4(-0.9,3.7)$ & $2.0(-0.8,4.8)$ \\
\hline \multicolumn{7}{|c|}{ Parameters of glucose metabolism } \\
\hline Glucose (mmol/L) & $4.6 \pm 0.7$ & $4.5 \pm 0.7$ & $0.2(-0.1,0.4)$ & $0.2(-0.0,0.5)$ & $0.3(0.1,0.6)^{*}$ & $0.4(0.1,0.7)^{* *}$ \\
\hline Insulin (pmol/L) & $107.2 \pm 51.5$ & $112.4 \pm 94.6$ & $-5.8(-25.6,13.8)$ & $2.5(-22.6,27.6)$ & $28.1(-11.4,67.6)$ & $13.2(-25.5,51.9)$ \\
\hline HOMA-IR & $3.44 \pm 1.66$ & $3.24 \pm 1.96$ & $0.19(-0.55,0.94)$ & $0.45(-0.47,1.37)$ & $0.85(-0.00,1.72)$ & $0.89(-0.00,1.78)$ \\
\hline $\mathrm{HbA} 1 \mathrm{c}(\mathrm{mmol} / \mathrm{mol})$ & $32.7 \pm 2.9$ & $32.8 \pm 2.5$ & $0.1(-0.8,1.0)$ & $0.5(-0.4,1.5)$ & $0.7(-0.3,1.7)$ & $0.9(-0.2,2.0)$ \\
\hline C-peptide (nmol/L) & $0.9 \pm 0.3$ & $0.9 \pm 0.3$ & $0.0(-0.1,0.1)$ & $0.0(-0.1,0.1)$ & $0.1(-0.0,0.2)$ & $0.0(-0.1,0.2)$ \\
\hline
\end{tabular}

Note: Estimated effect changes are based upon imputated datasets. $P$-values are based upon comparison with baseline values. ${ }^{*} P<.05 ;{ }^{* *} P<.01$.

Abbreviations: BMI, body mass index; cpd, counts per day; cpm, counts per minute; En\%, percentage of total energy intake; FFM, fat free mass; FM, fat mass; HOMA-IR, Homeostatic Model Assessment of Insulin Resistance [glucose (mmol/L)/insulin (mU/L) $\times 22,5-{ }^{34}$ ]; HP, high protein/low glycaemic index; MP, medium protein/medium glycaemic index; PA, physical activity; TFEQ, Three Factor Eating Questionnaire. ${ }^{35}$

intervention in the HP and MP group (Table 1). No significant differences were observed between the two intervention groups regarding dietary intake, despite TFEQ scores indicating an increase in cognitive dietary restraint over time.

\section{3 | Effects of the dietary intervention on IR, metabolic and anthropometric parameters}

No significant differences were observed between the two intervention groups regarding IR, parameters of glucose metabolism, anthropometric characteristics or lifestyle factors at any timepoint (Table 2).

\section{4 | DISCUSSION}

This PREVIEW study aimed to assess the effects of a high protein/ low GI vs a medium protein/medium GI diet on IR in adolescents with overweight and obesity and IR. No significant differences were found in reported protein intake and $\mathrm{Gl}$ between the two intervention groups, despite groups receiving different dietary instructions. No significant differences were observed between the two intervention groups regarding IR, parameters of glucose metabolism, anthropometric characteristics or lifestyle factors at any timepoint. We conclude that the study was not feasible.

Lack of feasibility was due to poor retention rates and lack of dietary compliance. Retention rates were $66 \%$ after 1 year and $39 \%$ after 2 years. The HP group did not achieve the protein target of $25 \mathrm{En} \%$ and reported protein intake was not significantly different between the two intervention groups. One possible explanation might be that the protein intake estimates were based upon self-reported food diaries, which are known to be underreported. ${ }^{42}$ Reported energy intake was $32.6 \%$ to $62.1 \%$ lower than the energy requirements according to the WHO formula for adolescents of corresponding ages and weights. ${ }^{29}$ The unmet protein target might partly be explained by reduced reward mechanisms in the brain or costs of high-protein foods. ${ }^{43}$ Previous studies aiming to increase relative protein intake in adolescents also reported difficulties in dietary compliance. ${ }^{11,13-18}$ Only half of them observed a difference in protein En\% between the higher-protein and the control group, which was often lower than the targets set between 22.5 and 25.0 En\%. ${ }^{14,16,18}$ None of the studies 
observed a difference in BMI z-score decrease between intervention groups. The results from this study imply that achieving and maintaining a high protein/low Gl diet during 2 years is not feasible with instructions alone. Achieving and maintaining an energy target of 25 En\% protein might only be feasible with vouchers/subsidies for foods high in protein, the use of protein supplements or meal replacements. Although an increase in cognitive dietary restraint over time was observed, indicating general attention for dieting, this appeared to be insufficient to contribute to compliance to the specific diets.

Furthermore, HOMA-IR stabilized after 1 and 2 years of lifestyle intervention, despite progression in pubertal stage. As described previously, transient pubertal IR typically nadirs at mid-puberty, suggesting that the PREVIEW lifestyle intervention prevented further IR increase. 5,6 Half of the previously performed studies where reported protein intake did increase significantly observed a reduction in HOMA-IR in adolescents with an increased-protein diet. ${ }^{11,12,14}$ However, these studies did not take pubertal stage into account.

By including all adolescents at increased risk of T2DM, regardless of age or specific obesity status, the study design was placed in a real life setting. Limitations were the use of HOMA-IR as a proxy of IR, and absence of an untreated control group due to ethical considerations of performing research in adolescents. In addition, no qualitative data were required on why participants did not meet the protein target and costs of diets was not considered in this study.

In conclusion, the PREVIEW study observed no effect of a high protein/low GI diet on IR in adolescents with overweight/obesity and IR because of lack of feasibility due to insufficient retention and dietary compliance.

\section{ACKNOWLEDGEMENTS}

The authors are very grateful to the adolescents and families that have participated in the PREVIEW study and the entire PREVIEW consortium for their contribution to the study. The study has received a grant from the EU 7th Framework Programme (FP7-KBBE-2012, grant no. 312057).

\section{CONFLICTS OF INTEREST}

The authors declare no conflict of interest.

\section{AUTHOR CONTRIBUTIONS}

Anita Vreugdenhil, Margriet Westerterp-Plantenga and Anne Raben designed the study. Elke Dorenbos, Mathijs Drummen, Jesse Rijks, Santiago Navas-Carretero, Nils Swindell, Pauline Stouthart, Kelly Mackintosh and Melitta Mcnarry carried out the experiments. Elke Dorenbos, Bjorn Winkens and Tanja Adam analyzed the data. Elke Dorenbos, Anita Vreugdenhil and Margriet Westerterp-Plantenga wrote the paper. All authors were involved in revision and final approval of the submitted version.

\section{ORCID}

Elke Dorenbos (iD https://orcid.org/0000-0001-8675-9672

Anita Vreugdenhil (D) https://orcid.org/0000-0003-1499-5937

\section{REFERENCES}

1. Lobstein T, Jackson-Leach R. Planning for the worst: estimates of obesity and comorbidities in school-age children in 2025. Pediatr Obes. 2016;11(5):321-325.

2. Olds T, Maher C, Zumin S, et al. Evidence that the prevalence of childhood overweight is plateauing: data from nine countries. Int J Pediatr Obes. 2011;6(5-6):342-360.

3. Skinner AC, Skelton JA. Prevalence and trends in obesity and severe obesity among children in the United States, 1999-2012. JAMA Pediatr. 2014;168(6):561-566.

4. Chiavaroli V, Giannini C, D'Adamo E, et al. Weight loss in obese prepubertal children: the influence of insulin resistance. Endocr Res. 2013;38(1):48-57.

5. Cree-Green M, Triolo TM, Nadeau KJ. Etiology of insulin resistance in youth with type 2 diabetes. Curr Diab Rep. 2013;13(1):81-88.

6. Dorenbos E, Rijks JM, Adam TC, Westerterp-Plantenga MS, Vreugdenhil AC. Sleep efficiency as a determinant of insulin sensitivity in overweight and obese adolescents. Diabetes Obes Metab. 2015; 17(Suppl 1):90-98.

7. Lee JM. Insulin resistance in children and adolescents. Rev Endocr Metab Disord. 2006;7(3):141-147.

8. Levy-Marchal C, Arslanian S, Cutfield W, et al. Insulin resistance in children: consensus, perspective, and future directions. J Clin Endocrinol Metab. 2010;95(12):5189-5198.

9. Xu L, Li M, Yin J, et al. Change of body composition and adipokines and their relationship with insulin resistance across pubertal development in obese and nonobese Chinese children: the BCAMS study. Int J Endocrinol. 2012;2012:389108.

10. Skinner AC, Perrin EM, Moss LA, Skelton JA. Cardiometabolic risks and severity of obesity in children and young adults. N Engl J Med. 2015;373(14):1307-1317.

11. Baxter KA, Ware RS, Batch JA, Truby H. Predicting success: factors associated with weight change in obese youth undertaking a weight management program. Obes Res Clin Pract. 2013;7(2):e147e154.

12. Damsgaard CT, Papadaki A, Jensen SM, et al. Higher protein diets consumed ad libitum improve cardiovascular risk markers in children of overweight parents from eight European countries. J Nutr. 2013; 143(6):810-817.

13. Duckworth LC, Gately PJ, Radley D, Cooke CB, King RF, Hill AJ. RCT of a high-protein diet on hunger motivation and weight-loss in obese children: an extension and replication. Obesity. 2009;17(9):18081810.

14. Garnett SP, Gow M, Ho M, et al. Improved insulin sensitivity and body composition, irrespective of macronutrient intake, after a 12 month intervention in adolescents with pre-diabetes; RESIST a randomised control trial. BMC Pediatr. 2014;14:289.

15. Gately PJ, King NA, Greatwood HC, et al. Does a high-protein diet improve weight loss in overweight and obese children? Obesity. 2007;15(6):1527-1534.

16. Mirza NM, Palmer MG, Sinclair KB, et al. Effects of a low glycemic load or a low-fat dietary intervention on body weight in obese Hispanic American children and adolescents: a randomized controlled trial. Am J Clin Nutr. 2013;97(2):276-285.

17. Papadaki A, Linardakis $M$, Larsen TM, et al. The effect of protein and glycemic index on children's body composition: the DiOGenes randomized study. Pediatrics. 2010;126(5):e1143e1152.

18. Rolland-Cachera MF, Thibault H, Souberbielle JC, et al. Massive obesity in adolescents: dietary interventions and behaviours associated with weight regain at 2 y follow-up. Int J Obes Relat Metab Disord. 2004;28(4):514-519.

19. Noakes M. The role of protein in weight management. Asia Pac J Clin Nutr. 2008;17(Suppl 1):169-171. 
20. Ludwig DS, Majzoub JA, Al-Zahrani A, Dallal GE, Blanco I, Roberts SB. High glycemic index foods, overeating, and obesity. Pediatrics. 1999; 103(3):E26.

21. Bell LM, Watts K, Siafarikas A, et al. Exercise alone reduces insulin resistance in obese children independently of changes in body composition. J Clin Endocrinol Metab. 2007;92(11):4230-4235.

22. Ho M, Garnett SP, Baur LA, et al. Impact of dietary and exercise interventions on weight change and metabolic outcomes in obese children and adolescents: a systematic review and meta-analysis of randomized trials. JAMA Pediatr. 2013;167(8):759-768.

23. Shaibi GQ, Cruz ML, Ball GD, et al. Effects of resistance training on insulin sensitivity in overweight Latino adolescent males. Med Sci Sports Exerc. 2006;38(7):1208-1215.

24. Shaw M, Savoye M, Cali A, Dziura J, Tamborlane WV, Caprio S. Effect of a successful intensive lifestyle program on insulin sensitivity and glucose tolerance in obese youth. Diabetes Care. 2009;32(1):45-47.

25. Savoye M, Shaw M, Dziura J, et al. Effects of a weight management program on body composition and metabolic parameters in overweight children: a randomized controlled trial. JAMA. 2007;297(24): 2697-2704.

26. Savoye M, Caprio S, Dziura J, et al. Reversal of early abnormalities in glucose metabolism in obese youth: results of an intensive lifestyle randomized controlled trial. Diabetes Care. 2014;37(2): 317-324.

27. Hirst K, Baranowski T, DeBar L, et al. HEALTHY study rationale, design and methods: moderating risk of type 2 diabetes in multi-ethnic middle school students. Int J Obes. 2009;33(Suppl 4):S4-S2O.

28. Dorenbos E, Drummen M, Rijks J, et al. PREVIEW: prevention of diabetes through lifestyle intervention in a multicentre study in Europe in children (10-17y). Design, methods, and baseline results. Diabetes Obes Metab. 2018;20(5):1096-1101.

29. Energy and Protein Requirements. Report of a joint FAO/WHO/UNU Expert Consultation. World Health Organ Tech Rep Ser. 2013;724: 1-206.

30. de Onis $M$, Lobstein T. Defining obesity risk status in the general childhood population: which cut-offs should we use? Int I Pediatr Obes. 2010;5(6):458-460.

31. Lohman TG, Hingle M, Going SB. Body composition in children. Pediatr Exerc Sci. 2013;25(4):573-590.

32. Marshall WA, Tanner JM. Variations in pattern of pubertal changes in girls. Arch Dis Child. 1969;44(235):291-303.
33. Marshall WA, Tanner JM. Variations in the pattern of pubertal changes in boys. Arch Dis Child. 1970;45(239):13-23.

34. Matthews DR, Hosker JP, Rudenski AS, Naylor BA, Treacher DF, Turner RC. Homeostasis model assessment: insulin resistance and beta-cell function from fasting plasma glucose and insulin concentrations in man. Diabetologia. 1985;28(7):412-419.

35. Stunkard AJ, Messick S. The three-factor eating questionnaire to measure dietary restraint, disinhibition and hunger. J Psychosom Res. 1985;29(1):71-83.

36. Vogels N, Diepvens K, Westerterp-Plantenga MS. Predictors of longterm weight maintenance. Obes Res. 2005;13(12):2162-2168.

37. Vogels N, Westerterp-Plantenga MS. Categorical strategies based on subject characteristics of dietary restraint and physical activity, for weight maintenance. Int J Obes (Lond). 2005). 2005;29(7):849-857.

38. Vogels N, Westerterp-Plantenga MS. Successful long-term weight maintenance: a 2-year follow-up. Obesity. 2007;15(5):1258-1266.

39. Baecke JA, Burema J, Frijters JE. A short questionnaire for the measurement of habitual physical activity in epidemiological studies. Am J Clin Nutr. 1982;36(5):936-942.

40. Rich C, Geraci M, Griffiths L, Sera F, Dezateux C, Cortina-Borja M. Quality control methods in accelerometer data processing: defining minimum Wear time. PLoS One. 2013;8(6):e67206.

41. Evenson KR, Catellier DJ, Gill K, Ondrak KS, McMurray RG. Calibration of two objective measures of physical activity for children. J Sports Sci. 2008;26(14):1557-1565.

42. Heitmann BL, Lissner L, Osler M. Do we eat less fat, or just report so? Int J Obes Relat Metab Disord. 2000;24(4):435-442.

43. Born JM, Martens MJ, Lemmens SG, Goebel R, WesterterpPlantenga MS. Protein v. carbohydrate intake differentially affects liking- and wanting-related brain signalling. Br J Nutr. 2013;109(2): 376-381.

How to cite this article: Dorenbos E, Drummen M, Adam T, et al. Effect of a high protein/low glycaemic index diet on insulin resistance in adolescents with overweight/obesity-A PREVIEW randomized clinical trial. Pediatric Obesity. 2020; e12702. https://doi.org/10.1111/ijpo.12702 